\title{
A dinâmica produtiva agrícola no espaço fronteira Brasil - Uruguai e suas contribuições na construção de sujeitos territoriais
}

TATIANE ALMEIDA NETTO

> Universidade Federal de Santa Maria, Santa Maria, Brasil. tatinetto@yahoo.com.br LETÍCIA FÁTIMA DE AZEVEDO

> Universidade Federal de Santa Maria, Santa Maria, Brasil. letiazevedo@hotmail.com

Universidad de Valparaíso

Facultad de Arquitectura

Revista Márgenes

Espacio Arte Sociedad

A dinâmica produtiva agrícola no espaço fronteira Brasil - Uruguai

e suas contribuições na construção de sujeitos territoriais

Septiembre 2016 Vol. 13 Nº 18

Páginas 55 a 60

ISSN elec. 0719-4463

ISSN imp. 0718-4034

Recepción: septiembre 2015

Aceptación: noviembre 2015

RESUMO

Os avanços de novos sistemas de produção no espaço rural e a permanente transformação em mudanças físicas e socioeconômicas deste espaço demandam um estudo de abordagem territorial para que se perceba a dialética existente entre os diversos sujeitos sociais em disputa de poder, regidos pela nova ordem econômica de desenvolvimento. A zona de fronteira entre Brasil e Uruguai é o objeto de estudo desta pesquisa, por se tratar de uma área que abriga um alto grau de fluxo e interação entre países e incide diretamente na promoção do desenvolvimento territorial e organização do espaço. A pesquisa tem como objetivo descrever a influência da dinâmica produtiva no surgimento de outros sujeitos e atores em consonância com a presença do capital. Metodologicamente utilizam-se de instrumentos como a pesquisa documental, bibliográfica, observação direta e entrevista semiestruturada com informantes qualificados utilizando-se do método dialético e a abordagem qualitativa para análise dos dados. Como resultado aponta-se a territorrialização da cadeia da soja e da silvicultura que interferem na composição da estrutura agrária atual, constituída por empresários agrícolas- pecuaristas fortemente modernizados integrados a complexos agroindustriais e a presença de agricultores familiares integrados a cadeia produtiva (soja, silvicultura) através da pluriatividade e estratégias de acesso à terra. PALAVRAS-CHAVE

capital, globalização, desenvolvimento, território, fronteira

\section{The dynamics productive agricultural frontier in Brazil - Uruguay space and contributions in subjects of construction and regional ABSTRACT}

Advances of new production systems in rural areas and ongoing transformation in physical and socioeconomic changes this space demand a territorial approach to study so that they realize the existing dialectics between the different social subjects in dispute of power, governed by the new economic order development. The border area between Brazil and Uruguay is the object of study of this research, because it is an area that is home to a high degree of flow and interaction between countries and focuses directly on the promotion of regional development and organization of space. The research aims to describe the influence of productive dynamics in the emergence of other subjects and actors in line with the presence of the capital. Methodologically are used instruments such as documentary research, literature, direct observation and semi-structured interviews with qualified informants using the dialectical method and qualitative approach to data analysis. As a result points to territorrialização soybean chain and forestry that interfere in the composition of the current agrarian structure, consisting of farmers agrícolas- entrepreneurs strongly modernized the integrated agro-industrial complex and the presence of family farmers integrated production chain (soy, forestry) through pluriactivity and land access strategies.

KEYWORDS

capital, globalization, development, territory, border 


\section{INTRODUÇÃO}

Vários impactos são decorrentes da globalização e da presença do capital junto a dinâmica agrícola, acarretando transformações territoriais, logo, sociais. Para entendermos a questão agrária contemporânea, devemos compreender as evoluções presentes na agricultura com a introdução do capitalismo, do trabalho assalariado no campo, da modernização agrícola e da multifuncionalidade deste espaço.

A questão agrária na contemporaneidade é produto da dominação e resistência do capital resultantes da expropriação, concentração da terra e das riquezas que procedem em formas de organização social incongruentes em um mesmo espaço gerados pela conflitualidade em disputa por território (Fernandes, 2008).

O cenário da globalização resulta em transformações territoriais e sociais oriundas de novas relações de produção com a introdução de novos cultivos, em reposta à dinâmica agrícola-industrial-produtiva de organização do espaço em redes. Observa-se a presença de redes articuladas pela racionalidade econômica, nas quais Flores (1998) destaca que a empresa transnacional global não possui um centro geográfico, nacionalidade ou personalidade e necessita sempre ampliar as fronteiras a procura de mercado.

A modernização e a presença do capitalismo resultam em uma agricultura com um modelo de crescimento vinculado a uma estrutura produtiva, fordista e tecnológica, com pacotes tecnológicos difundidos/ exigidos pelas empresas processadoras de alimentos. Incorpora-se na agricultura moderna o trabalho industrial, exigindo dos produtores um comportamento empresarial e não mais familiar, condicionando a presença de trabalhadores assalariados (Flores, 1998).

A dinâmica agrícola se transforma a partir da abordagem do capitalismo agrário, através da flexibilização da agricultura e das complexas relações da natureza com a sociedade, que moldam as formas de produção e mercado presentes neste espaço. A agricultura flexível acarreta na diversificação produtiva, na incorporação de novas tecnologias e descentralização das empresas transnacionais com formação de redes e novas formas de organização do trabalho que se adaptam e se reorganizam e até refuncionalizam formas de produção tradicionais (Flores, 1998).

Os temas da globalização, da presença de capital estrangeiro, da industrialização, da agricultura flexível interferem diretamente na estrutura social agrária provocando tensões territoriais. Estas tensões territoriais estão presentes no espaço fronteira Brasil - Uruguai. Vários estudos apontam a expansão agrícola no Uruguai e o fortalecimento da cadeia de soja no Brasil. Brasil e Uruguai através das políticas de incentivos realizadas pelo MERCOSUL aumentaram na última década os números de produção de commodities. Entre 2000 e 2011, as reservas internacionais do Brasil e Uruguai cresceram 958\% (de US $\$ 33,4$ bilhões para US $\$ 353,8$ bilhões) e $270,2 \%$ (de US $\$ 2,8$ bilhões para US $\$ 10,4$ bilhões), respectivamente (Pinto, 2013).

Sendo assim, o presente trabalho tem por objetivo descrever a influência da dinâmica produtiva no surgimento de outros sujeitos e atores em consonância com a presença do capital.

\section{METODOLOGIA}

A pesquisa considera-se um estudo exploratório e descritivo e se utiliza de ferramentas como a pesquisa bibliográfica, observação direta e pesquisa documental através da coleta de dados dos Cen- sos do Instituto Brasileiro de Geografia e Estatística (IBGE), do Censo 2011 Uruguay Instituto Nacional de Estadística (INE), do Censo Agropecuário 2011 Estadísticas Agropecuárias (DIEA) vinculados ao Ministerio de Ganadería, Agricultura y Pesca (MGAP).

A área de estudo desta pesquisa se concentra no espaço denominado zona de fronteira Brasil - Uruguai, com recorte intencional para as cidades gêmeas de Santana do Livramento e Departamento de Rivera. 0 recorte se faz necessário para apresentação da transformação da dinâmica agrária na fronteira nas últimas duas décadas, para tanto, foram realizadas 10 entrevistas semiestruturadas através da mobilidade acadêmica da AUGM de uma das autoras em setembro de 2014. As entrevistas foram realizadas com informantes chaves, entre eles: técnicos privados e/ou públicos, órgãos diretivos de fomento, instituições públicas e de ensino. Os entrevistados foram indicados pela UDELAR através da Unidad de Extensión e pela Sociedad de Fomento Rural de Rivera devida a efetiva participação dos informantes na fronteira Brasil - Uruguai.

\section{O ESPAÇO FRONTEIRA BRASIL - URUGUAI}

O espaço zona de fronteira Brasil - Uruguai compreende uma área de integração política, cultural e de identidade própria, não se limitando a uma divisão espacial de $150 \mathrm{~km}$ a partir da linha de transição em zona de fronteira.

Na zona de fronteira Brasil - Uruguai observamos a inserção de uma agricultura capitalista que se territorializa com as cadeias globais de valor, promovendo conflito e desenvolvimento e ao mesmo tempo expropriando o campesinato. A territorialização da cadeia da soja e da silvicultura pode ser visualizada na Figura 1.

O tema da globalização, da presença de capital estrangeiro, da industrialização, da agricultura flexível, a qual nos últimos 10 anos intensificam-se no território zona de fronteira Brasil - Uruguai, interferem diretamente na estrutura social agrária. A partir da abordagem do capitalismo agrário se moldam as formas de produção e mercado presentes neste espaço.

A partir de 2000 intensificam-se os estudos das cadeias globais de valor (CGV), nas quais através da fragmentação da produção em âmbito mundial, possibilitariam aos países em desenvolvimento uma via rápida de industrialização através da captura de etapas ou tarefas dos elos das cadeias de valor. Para tanto, organizações econômicas internacionais como Organização para a Cooperação e Desenvolvimento Econômico (OCDE), Banco Mundial, Organização Mundial do Comércio (OMC) e Conferência das Nações Unidas sobre Comércio e Desenvolvimento (UNCTAD) estimulam a intensificação das políticas de liberalização comercial (Veiga e Rios, 2014).

Embora as cadeias globais de valor, como o nome mesmo descreve, estejam inseridas mundialmente, autores como Baldwin, destacam uma regionalização destas cadeias em relação aos custos de deslocamento e as políticas comerciais (Veiga e Rios, 2014). A política de desenvolvimento economicista acarreta em acordos comerciais entre países vizinhos favorecendo o surgimento de cadeias regionais que alteram a dinâmica espacial frente à diversificação de sujeitos e compreendem tensões territoriais, uma vez que o território é fruto das relações de poder da diversidade destes sujeitos presentes neste espaço.

Tanto no Brasil como no Uruguai a priorização de exportação segue em produtos do setor primário com níveis relativamente baixos de processamento. Percebe-se uma maior intensificação da cadeia de 


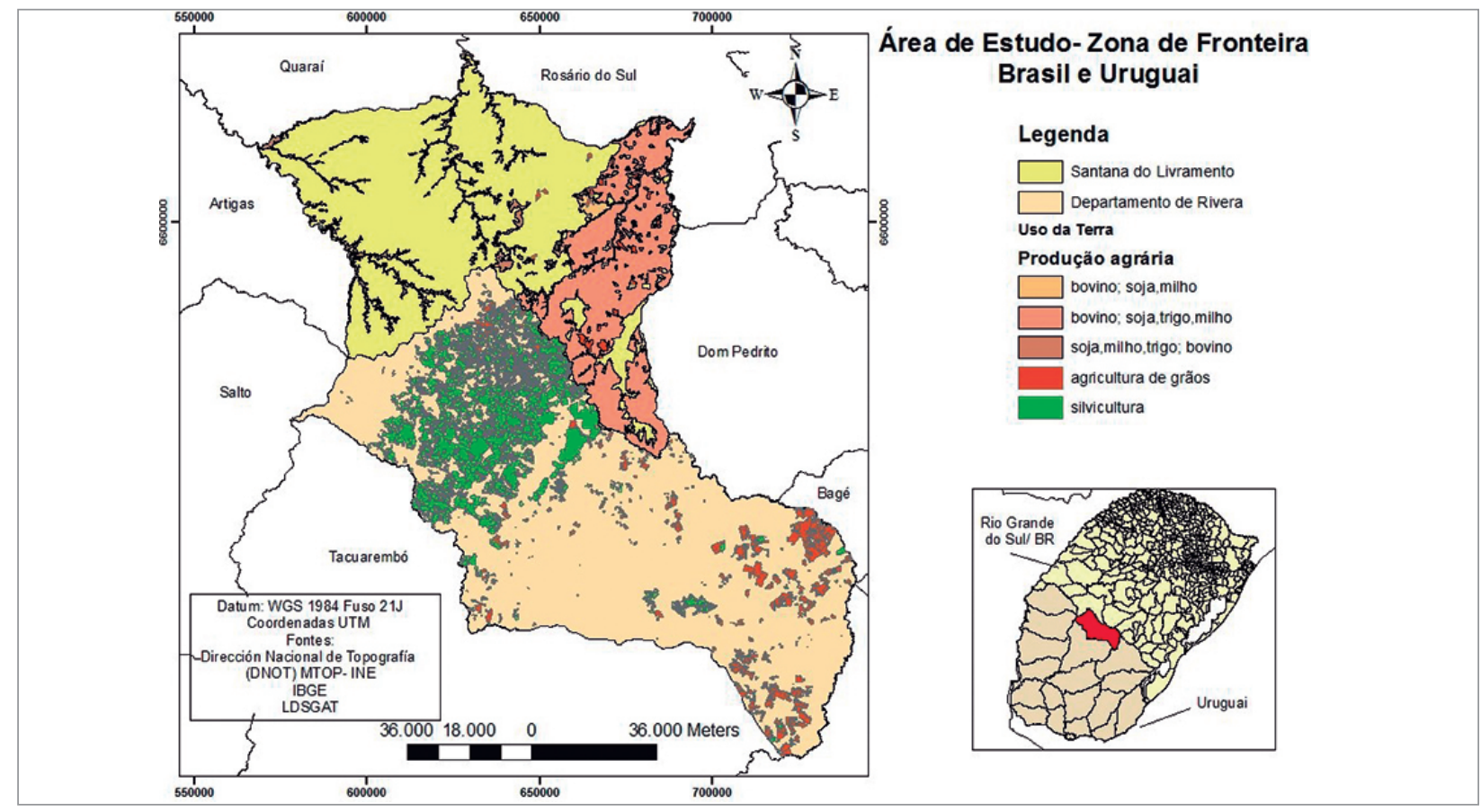

soja no lado brasileiro e da silvicultura no lado uruguaio, embora ambas estejam presentes na zona de fronteira, considerando que o principal parceiro comercial é a China. No Brasil entre 2000 e 2010 as exportações brasileiras para a China aumentaram quase 30 vezes (Sturgeon et al., 2013).

A exportação de commodities dos países do Mercosul para a China resultaram em expressivo superávit no balanço de pagamentos de US\$293,9 bilhões no acumulado entre 2000 e 2010, possibilitando aos países acumular expressivas reservas (de US\$ 62,4 bilhões em 2000 para US\$415,5 bilhões em 2011). Entre 2000 e 2011, as reversas internacionais do Brasil e Uruguai cresceram 958\% (de US\$ 33,4 bilhões para US\$353,8 bilhões) e 270,2\% (de US\$ 2,8 bilhões para US\$10,4 bilhões), respectivamente (Pinto, 2013).

Estudos referentes as cadeias globais de valor no Uruguai destacam a inserção de tecnologias, de novos modelos de gestão, junto a cadeia de agronegócio de cereais e oleaginosas, na produção de celulose e cadeia leiteira impulsionadas por políticas públicas e agropecuárias ampliando o mercado de compra e venda, assim como o arrendamento de terras e o trabalho assalariado rural (Paolino, 2014).

As relações impostas no território não são derivadas somente dos seres humanos e seu espaço, e sim de diversos atores, entre eles e o espaço, na qual as relações de inclusão e exclusão resultantes desta dinâmica agrícola, através da inserção das cadeias de valor, definem o território e a territorialidade.

A intensificação da expansão agrícola em zonas de pecuária tradicionais com a inserção da silvicultura e da soja alterou o uso e a ocupação da terra no Uruguai e no Brasil. Estudos referentes a expansão agrícola no Uruguai apontam que até o ano de 2006 isto se dava em áreas de pecuária tradicional e recentemente, após 2006 já se integram a áreas novas e com aptidão agrícola (Achkar et al., 2011).

Já no Brasil, especificamente na metade Sul do Estado do Rio Grande do Sul (RS), a agricultura até meados do século XX foi considerada uma atividade complementar, reduzida a uma cultura de subsistência, salvo as áreas orizícolas nas terras mais baixas da campanha gaúcha.

Figura 1. Mapa temático cadeia da soja e da silvicultura na zona de fronteira Brasil - Uruguai. Fonte: Elaboração do autor, 2015. 
Os estancieiros integrantes da metade sul do RS, portanto, pertencentes a área de fronteira, mantiveram-se por muito tempo em uma mesma atividade produtiva, pelo absoluto desconhecimento de outras formas de produzir. Mesmo quando a partir do final do século XIX a economia pecuária já se mostrava em declínio, em contraste com a policultura presente na metade norte do Estado, resultante de uma política governamental que visava a colonização e crescimento agrícola-industrial para a diversificação da economia do RS (Rocha, 2000).

Entretanto, hoje, se percebe na metade sul do RS, a inserção de cultivos de grãos como sorgo forrageiro, soja e milho. Recentemente, estão sendo incorporadas nas unidades familiares a fruticultura, tais como a produção de pêssego, laranja, bergamota, melancia e as videiras. Também há presença de horticultura na fronteira. Através de dados do IBGE (2014) visualiza-se um aumento em 5 vezes na área plantada de soja no município de Santana do Livramento, no ano de 2004 segundo dados da produção agrícola municipal apresentava 4.700 há de área plantada, já em 2013 segundo dados da produção agrícola municipal se apresenta 29.100 há de área plantada.

\section{A INFLUÊNCIA DA GLOBALIZAÇÃO E CONSEQUENTEMENTE DO CAPITAL}

As transformações territoriais podem resultar em perda da identidade local, na qual gera espaços produtivos, mas espaços sem representação política, social e totalmente dependente da economia global.

Haja vista, que os territórios são formados por uma relação híbrida entre global e local, a dinâmica agrícola presente neste espaço fronteira Brasil - Uruguai influencia diretamente as relações sociais, deste modo, os sujeitos presentes e resultantes desta dinâmica.

Segundo Abramovay (2007) ponderar sobre território favorece o avanço nos estudos dos espaços rurais ao menos em quatro dimensões básicas sendo elas: a multifuncionalidade, o desenvolvimento sustentável, o estudo empírico dos diversos sujeitos sociais e a relação entre sistemas sociais e ecológicos na organização produtiva deste espaço.

Atualmente se tem presente a influência da globalização, da informação, da tecnologia que dão origem ao capital virtual, resulta no território, na inserção de redes, onde os gigantes coorporativos se apropriam da biodiversidade, desterritorializam comunidades e destroem culturas (Bartra, 2006).

A agricultura hoje enfrenta cada vez mais mudanças tecnológicas em virtude do produtivismo do paradigma do capitalismo agrário. Flores (1998) aponta que as mudanças tecnológicas e a intensificação de pacotes tecnológicos emergem sempre no intuito de criar uma natureza com imagem e semelhança do capital, como exemplo, a inserção de transgênicos, nanotecnologia e agricultura de precisão.

A imposição da tecnologia ao agricultor interfere no uso dos saberes tradicionais e nas relações de produção. 0 campesino hoje, não tem como trabalhar fora da lógica do capital, pode não trabalhar para ele, mas se integra ao mercado e trabalha junto ao capital. Para Fernandes (2008) o camponês não se extingue e proletarizase, ao contrário do que pensava Lênin e Kaustky, ao acessarem a terra os trabalhadores se ressocializam, lutando contra o capital e também se subordinando a ele, se reinserindo na produção capitalista das relações não capitalistas de produção, pois na exclusão e geração do trabalho familiar criam e recriam relações sociais como arrendamento, parceria e meação.

O capital quando acessa o campo tem que diversificar tecnologias, modos de acesso à terra e padrões produtivos. A diversidade ecossistêmicas presentes no sistema produtivo interferem na produção, nos custos desta e consequentemente no lucro. Para tanto, o capital intervém com mecanismos de controle no mercado agrícola como: estatização de terras e água, fixação de preços em planos nacionais ou internacionais, intervenção estatal, intensificação em processos de desenvolvimento na estrutura agrícola para a produção, incentivo em programas de extensão rural e crédito agrícola, políticas de fomento, normatização no uso dos recursos naturais, fomento para a fixação e criação de cooperativas e na industrialização de mercado (Bartra, 2006).

\section{TRANSFORMAÇÃO NA DINÂMICA AGRÁRIA E FORMAÇÃO DE MÚLTIPLOS TERRITÓRIOS NA ZONA DE FRONTEIRA BRASIL - URUGUAI}

Muitos são os indícios e indicadores de uma transformação na dinâmica produtiva agrícola no espaço da zona de fronteira Brasil - Uruguai, impulsionados pelas políticas e acordos comerciais advindos da abertura ao capital internacional. Observa-se a formação de múltiplos territórios aliados aos espaços de governança, aos tipos de propriedades existentes, as formas de uso deste espaço, destacando-se a territorialização da soja, da silvicultura.

As perspectivas e alternativas de desenvolvimento do território estão cada vez mais dependentes das características dominantes, da economia mundial e dos modelos produtivos vigentes. Em relação a zona de fronteira os informantes observam a transformação no tradicional sistema produtivo, a pecuária de corte, que está dando espaço a agricultura, seja a silvicultura ou a soja. A soja aparece consorciada com a cultura de arroz, perdendo espaço para esta em razão da rentabilidade.

A demanda por alimentos e matéria prima favorecem países como Uruguai e Brasil a investirem na produção de matérias primas aliadas as cadeias globais de valor, na qual os países apostam em acordos de liberalização comercial, inovações nas tecnologias da informação e de comunicações e na logística, principalmente transporte. Essa lógica não fica fora do espaço zona de fronteira Brasil - Uruguai, prova disso é o aumento crescente da cadeia de soja e o fortalecimento da cadeia de silvicultura, este último especificamente no Departamento de Rivera.

Em questionamento aos informantes qualificados todos eles responderam ser visíveis as transformações na dinâmica produtiva na região da fronteira, em Rivera destacam a produção florestal, mais precisamente o plantio de Pinus e a produção madeireira como a principal transformação a ser visualizada pelo lado Uruguaio.

As unidades familiares presentes no espaço fronteira Brasil - Uruguai diversificam sua dinâmica produtiva, muito embora a grande maioria das unidades familiares ainda trabalhem com a pecuária extensiva em decorrência da inserção da cadeia de soja e silvicultura diversificam cada vez mais suas atividades para complementação de renda e apontam mudanças em seu comportamento para adaptação no meio social e econômico que se estabelece, seja vendendo sua força de trabalho para a produção silvícola ou arrendando terras para o plantio de soja e até arrendando áreas de florestamento das empresas para manter a prática da pecuária. 
Pode-se perceber na dinâmica multifuncional um resgate da importância do conjunto de contribuições da agricultura para a dinâmica econômico-social dos territórios, a multifuncionalidade emerge como resposta à crise dos agricultores advindas da modernização, na qual passam a adotar alternativas não agrícolas, chamadas hoje de pluriativas (Carneiro, 1998).

Ploeg (2008) aponta que a partir da década de 1990 surge uma tendência de novas formas de multifuncionalidade tais como: o desenvolvimento do agroturismo; a gestão agrária da natureza, da paisagem e da biodiversidade, a produção de energia, a produção, transformação e comercialização de produtos de alta qualidade e de especialidades regionais; os cuidados com pessoas deficientes; a retenção de água escassa, entre outras. E para o mesmo autor são quase sempre as unidades agrícolas camponesas que funcionam como ponto de partida para a criação desse tipo de entidades multifuncionais.

Na fronteira Brasil - Uruguai a transformação na dinâmica territorial é observada na diversidade de propriedades e na modernização das atividades. Apresentam a estrutura social dividida em: assalariados rurais, empresários rurais, campesinos e/ou produtores familiares.

O empresário rural é o que tem a posse da terra e emprega mão de obra assalariada (assalariados rurais), apresenta como dois subtipos distintos: o tradicional estancieiro que resiste a inversão tecnológica, domina e se mantém pelas grandes quantias de posse de terra. E o mais recente ator, o empresário "agrícola-ganadero", presente nas últimas quatro décadas do século XX (Piñeiro, 2012).

O empresário agropecuarista, ou seja, aquele que consorcia atividades agrícolas com pecuária realiza constantes inversões tecnológicas sobre a terra para garantir a produtividade, complementa sua produção pecuária com diversos cultivos agrícolas (arroz, cereais, oleaginosas, silvicultura).

Também se identifica nos produtores familiares, dois tipos: os capitalizados e os pluriativos. Deste modo, se inserem na lógica produtivista para se manter na atualidade, diversificando a produção e utilizando de tecnologias, quando não possuem capital de giro oferecem sua força de trabalho como mão de obra (pluriatividade) ocasionando característica relevante em relação a estrutura social do campo. 0 produtor familiar acaba por se tornar um assalariado rural possivelmente em função dos câmbios tecnológicos os quais não alcança (Piñeiro, 2012).

A presença da modernização no campo proporcionou a exigência de um novo perfil de trabalhadores rurais altamente qualificados, e como isso evidencia o surgimento de novos sujeitos territoriais, os técnicos especializados, também produtos desta nova lógica de globalização e da presença do capital, que favorece/incentiva a intensificação da ciência, da técnica e do conhecimento. No século XX, mudanças tecnológicas e a intensificação de pacotes tecnológicos emergem no intuito de criar uma natureza com imagem e semelhança do capital, a inserção de transgênicos, nanotecnologia e agricultura de precisão (Bartra, 2006).

Quando questionados os entrevistados sobre a intensificação de determinados sistemas produtivos e o desaparecimento de outros, os entrevistados relatam que a pecuária de corte segue sendo a característica da zona de fronteira, a produção se mantem. Ocorre aumento na rentabilidade da pecuária de corte, e aumento também no nível de escolaridade dos produtores, a pecuária de corte segundo a fala de um dos entrevistados [..] o negócio mudou de mão, são outros titulares das terras, os produtores se definem não como produtores e sim como empresários.
Em relação ainda a pecuária de corte e a fala do técnico entrevistado: o valor da terra é muito alto, antigamente não era atraente aumentar a produtividade ou fazer um investimento quando a terra valia tão pouco, e hoje não, a terra vale dez vezes mais do que valia, então, o que acontece hoje é que muitos desses produtores fazem investimentos fronteira adentro, não a fora. É muito difícil crescer porque o valor do arrendamento não está de acordo a produtividade. Segundo relatos desse entrevistado cada vez mais esses produtores que se denominam empresários e assim modificam sua racionalidade acabam por contratar mão de obra especializada para atuar na produção, sempre visando a rentabilidade, a produtividade.

Ainda se observa propriedades tradicionais, com baixo investimento e consequentemente baixa rentabilidade, em contraste com outras empresariais, com maior grau de investimento, como exemplo deste tipo de racionalidade empresarial se identifica as cabanhas que investem em aprimoramento zootécnico (genética). Podemos apontar as cabanhas como uma fase inicial na mudança do comportamento do pecuarista adotando um perfil mais empresarial, onde se iniciou a adoção do consórcio com a agricultura e o arrendamento da terra para a rizicultura (Costa, 1987).

Quando questionados os entrevistados sobre a continuidade destas transformações na dinâmica agrícola com a inserção da cadeia da soja e da silvicultura, as respostas são distintas. Um dos entrevistados acredita que a soja tende a diminuir em Rivera e se fixar em áreas do Brasil e do Paraguai devido as características ecossistêmicas dessa região. E em relação a silvicultura um dos entrevistados afirma que a área de plantio já chegou ao teto, ao máximo na região departamental de Rivera e, para ele o investimento deve ser em indústrias de beneficiamento da madeira.

Alguns apontam a tendência de instalação do agronegócio e das grandes empresas, que a agricultura em zona de fronteira já se instalou. Destacam que hoje, devido a esta dinâmica já se visualiza no Departamento de Rivera um êxodo rural cada vez maior, fenômeno observado pelo número de taperas, e que vilas rurais que continham cem (100) habitantes atualmente não passam de dez (10). Nesse sentido merece destaque a fala de um dos entrevistados ao desparecer os pequenos produtores desaparece a cadeia de produção. Os entrevistados relataram a diminuição na produção da cadeia de fumo, da cadeia ovina, da cadeia leiteira, devido à redução no número de produtores, a venda de suas propriedades e a inserção destes em novas atividades.

\section{CONSIDERAÇÕES FINAIS}

Ao considerarmos a questão agrária compreendemos que o capital adentra a natureza, privatizando os recursos e valorando-os, assim como intervém na reprodução social, favorecendo a proletarização do trabalho e a privatização da terra. o capital junto a agricultura com a finalidade de produzir mercadorias acaba por substituir as habilidades e saberes tradicionais por tecnologias propícias a intensificação e massificação dos processos produtivos. Assim, a presença da modernização influencia na construção dos sujeitos territoriais, pois incide diretamente nas relações destes sujeitos que modificam a organização e a identidade deste espaço.

A presença de uma transformação na dinâmica agrícola com a intensificação e, portanto, a territorialização da soja e da silvicultura na zona de fronteira Brasil - Uruguai interferem diretamente nas relações sociais advindas desta dinâmica. A territorialização destas cadeias surgem acompanhadas da concentração e estrangei- 
rização da terra que resultam em processos de êxodo e migração rural de produtores familiares em consequência do aumento do preço da terra. Os sujeitos territoriais presentes que convivem com esta transformação, os produtores familiares, sejam eles capitalizados ou pluriativos se consolidam com a introdução de técnicas e manejos, onde o produtor cada vez mais se atualiza em busca da produtividade e sustentabilidade de seu sistema apresentando um aumento em pastagens artificiais, campos melhorados fertilizados, e a introdução de cultivos forrageiros anuais. Esta dinâmica proporciona ainda o surgimento de novos sujeitos tais como o técnico especializado produto da presença do capital, que favorece e incentiva a intensificação da ciência, da técnica e do conhecimento.

Os produtores familiares presentes na zona de fronteira inserem-se na lógica produtivista para se manter na atualidade, diversificam a produção (fumo, fruticultura, apicultura, psicultura...) e, utilizam cada vez mais de tecnologias, e quando não possuem capital de giro oferecem sua força de trabalho como mão de obra (pluriatividade). As entrevistas e os dados secundários apontaram os pecuaristas como sendo os produtores representativos e os mesmos na atual conjuntura e dinâmica agrícola produzem novas relações sociais, como o arrendamento de áreas de empresas florestais para o pastoreio do gado e a venda da força de trabalho na cadeia florestal, seja no momento do plantio ou da colheita.

Por fim conclui-se que os impactos diretos e indiretos da globalização na zona de fronteira Brasil - Uruguai configuram uma nova realidade e identificam modificações na estrutura social, nas estratégias produtivas intensificando a reestruturação social.

\section{REFERÊNCIAS BIBLIOGRÁFICAS}

ABRAMOVAY, R. (2007) Para uma teoria dos estudos territoriais, In: Ortega, A. C. e Filho, N. A. (org.), Desenvolvimento Territorial, Segurança Alimentar e Economia Solidária, Campinas: Alínea editora.

ACHKAR, M.; DOMINGUEZ, A.; DÍAZ, I.; PESCE, F. (2011) La intensificación del uso agrícola del suelo en el litoral oeste del Uruguay en la última década, Pampa Nº7, Suplemento especial temático.

BARTRA, A. (2006) Del Capitán Swing a José Bové: los trabajadores del campo contra el hombre de hierro, In: Análisis Latinoamericano del medio rural, Nueva época $\mathrm{N}^{\circ} 4$, VII Congreso de la Asociación Latinoamericana de Sociología Rural (ALASRU), Universidad Autónoma de Chapingo, México, pp. 137-156.

CARNEIRO, M. J. (1998) Ruralidade: novas identidades em construção, In: Estudos Sociedade Agricultura, $N^{\circ} 11$, Out, Rio de Janeiro: CPDA-UFRRJ, pp. 53-75.

COSTA, R. H. da. (1987) Os agentes modeladores do novo espaço capitalista da campanha gaúcha, Boletim Gaúcho de Geografia, 15: 03-18.

DIÁRIO OFICIAL DA UNIÃO (DOU) (2014) Portaria Nº 115, Estabelece o conceito de cidades-gêmeas nacionais, os critérios adotados para essa definição e lista todas as cidades brasileiras por estado que se enquadram nesta condição, p. 45, Seção 1, Diário Oficial da União (DOU) de 24 de Março.
FERNANDES, B. M. (2008) Questão agrária: conflitualidade e desenvolvimento territorial, In: Buainain, A. M. (Ed), Luta pela terra, reforma agrária e gestão de conflitos no Brasil, Campinas: Editora da Unicamp.

FLORES, S. M. (1998) Globalización económica y flexibilidad productiva en la agricultura, In: Nuevas experiencias productivas y nuevas formas de organización del trabajo en la agricultura mexicana, México: Juan Pablos Editor, pp. 60-92.

INSTITUTO BRASILEIRO DE GEOGRAFIA E ESTATÍSTICA - IBGE (2014) Produção Agrícola Municipal 2013, Rio de Janeiro: IBGE.

LUCENA, M. G. (2011) Territorialidade de fronteira: uma contribuição ao estudo da questão fronteiriça Brasil - Uruguai no contexto do Mercosul, tese de doutorado, CPDA/UFFRJ, RJ.

PAOLINO, C. (2014) Las Transformaciones Estructurales en el Sector Agroalimentario: el caso de Uruguay, Revista Paranaense de Desenvolvimento, Curitiba, v. 35, N¹27, pp. 79-97.

PINTO, E. C. (2013) A dinâmica dos Recursos Naturais no Mercosul na década de 2000: "efeito China", estrutura produtiva, comércio e investimento estrangeiro, Texto para discussão, IE-UFRJ.

PIÑEIRO, D. E. (2012) Asalto a la Tierra: el capital financiero descubre el campo uruguayo, In: (Org.) Almeyra, G.; Pereira, J. M. M.; Concheiro, L.; Porto-Gonçalves, C. W., Capitalismo, terra e poder na América Latina (1982-2012), México: Editora Siglo XXI.

PLOEG, J. D.V. (2008) Camponeses e impérios alimentares: lutas por autonomia e sustentabilidade na era da globalização, Porto Alegre: Ed. da UFRGS.

REIS, C. F. de B.; ALMEIDA, J. C. G. de. (2014), A inserção do Brasil nas cadeias globais de valor comparativamente aos BRIICS, Texto para discussão n. 233, Campinas: IE/ UNICAMP.

ROCHA, J. M. da (2000) As raízes do declínio econômico da "Metade Sul" do Rio Grande do Sul - uma análise da racionalidade econômica dos agentes produtivos da região, In: Primeiras Jornadas de História Regional Comparada, Anais..., Porto Alegre: Fee, disponível em: http://www.fee. com.br/sitefee/download/jornadas/1/s12a5.pdf, acesso 12.12.2015

STURGEON, T.; GEREFFI, G.; GUINN, A.; ZYLBERBERG, E. (2013) O Brasil nas cadeias globais de valor: implicações para a política industrial e de comércio, Revista brasileira de comércio exterior - RBCE, No 115, jun 2013, disponivel em: http://www.funcex.org.br/publicações/rbce/material/ rbce/115_TSGGAGEZ.pdf, acesso 24.02.2015.

VEIGA, P. da M.; RIOS, S. P. (2014) Cadeias globais de valor e implicações para a formulação de políticas. Texto para discussão, Diretoria de Estudos em Relações Econômicas e Políticas Internacionais (Dinte) do Ipea, Instituto de Pesquisa Econômica Aplicada - Brasília, Rio de Janeiro: Ipea.

$\S$ 